\title{
SOME QUANTITATIVE RELATIONS BETWEEN INDOOR ENVIRONMENTAL QUALITY AND WORK PERFORMANCE OR HEALTH
}

\author{
Olli A Seppänen ${ }^{1}$, William J Fisk ${ }^{2}$ \\ ${ }^{1}$ Helsinki University of Technology \\ Finland \\ ${ }^{2}$ Lawrence Berkeley National Laboratory \\ Environmental Energy Technology Division \\ Indoor Environment Department \\ Berkeley, CA 94720
}

February 2006

This work was supported by the Academy of Finland. This work was also supported by the Indoor Environments Division, Office of Radiation and Indoor Air, Office of Air and Radiation of the U.S. Environmental Protection Agency through interagency agreement DW89-92175001-0 with the U.S. Department of Energy. This work was also supported by the Assistant Secretary for Energy Efficiency and Renewable Energy, Office of Building Technology of the U.S. Department of Energy under contract DE-AC03-76SF00098. 
Accepted for publication in ASHRAE Research Journal 2006

\author{
Olli A Seppänen ${ }^{1} \quad$ William J Fisk $^{2}$ \\ ASHRAE Fellow ASHRAE Member \\ ${ }^{1}$ Helsinki University of Technology, Finland \\ ${ }^{2}$ Lawrence Berkeley National Laboratory, USA
}

\title{
SOME QUANTITATIVE RELATIONS BETWEEN INDOOR ENVIRONMENTAL QUALITY AND WORK PERFORMANCE OR HEALTH
}

\begin{abstract}
Poor indoor environmental quality (IEQ) has been related to increases in sick building syndrome symptoms, respiratory illnesses, sick leave, and losses in productivity. Calculations indicate that the cost of poor IEQ can be higher than energy costs space conditioning and ventilation, and that many measures taken to improve indoor IEQ will be highly cost-effective when accounting for the monetary savings resulting from an improved health or productivity.

To enable building professionals to make selections of building designs and operating practices that account for effects on health and productivity, we need models for quantifying the health and productivity benefits of better indoor environments. Therefore, we have reviewed the literature on the effects of indoor environment on health and performance and used existing data, when possible, to develop some initial models. Based on the best-available evidence we present quantitative relationships between ventilation rate and short term sick leave, ventilation rate and work performance, perceived air quality and performance, temperature and performance, and temperature and sick building syndrome symptoms. We show also that a relationship exists between SBS symptoms (sick building syndrome symptoms) and work performance.
\end{abstract}

\section{INDEX TERMS}

Ventilation, Temperature, Performance, Modeling, Perceived air quality, SBS symptoms, Cost benefit calculations

\section{INTRODUCTION}

There is increasing evidence that indoor environmental conditions substantially influence health and performance. Building professionals are interested in improving indoor environments and quantifying the effects. Macro-economic estimates of nationwide financial gains have been developed. They show that the potential benefits from indoor environmental improvements for the society are high (Fisk 2000, 2001). Some calculations show that the estimated cost of poor indoor environment is higher than energy costs of heating and ventilation of the same buildings (Seppänen 1999). A few sample calculations have also shown that many measures to improve indoor air environment are cost-effective when the health and productivity benefits resulting from an improved indoor climate are included into the calculations (Djukanovic et al. 2002, Fisk 2000, Fisk et al. 2003, Hansen 1997, Seppänen and Vuolle 2000, Tuomainen et al. 2002, Wargocki, 2003). There is an obvious need to 
develop tools and models so that economic outcomes of health and performance can be integrated in cost benefit calculations with initial, energy and maintenance costs. The use of such models would be expected to lead to improved indoor environments, health and productivity. To systemize these building level calculations we have earlier developed a conceptual model (Seppänen and Fisk 2003) to estimate the cost-effectiveness of retrofits of indoor environment. In this paper we derive and present estimates of some quantitative linkages in the model for cost benefit calculations namely between ventilation rate and sick leave, ventilation rate and performance, perceived air quality and performance, temperature and performance, and temperature and SBS symptoms (sick building syndrome symptoms). We also suggest that a link between SBS symptoms and performance exists, and that a linkage from building factors to SBS symptoms and further to performance and health outcomes will be an attractive way to evaluate the financial benefits of indoor environmental improvements.

\section{VENTILATION RATES AND SHORT TERM SICK LEAVE}

Ventilation reduces the indoor concentration of indoor-generated airborne pollutants. The effects of ventilation rates on human responses has been summarized by Seppänen at al. (1999), Fisk (2000) and Wargocki et al. (2002). These summaries show that the prevalence of some types of communicable respiratory diseases is higher under conditions with lower ventilation rates. In our earlier paper (Fisk et al. 2003) a quantitative relationship between ventilation rate and sick leave was estimated combining published field data and a theoretical model of airborne transmission of respiratory infections. The model (Figure 1) accounts for the effects of ventilation, filtration, and particle deposition on airborne concentrations of infectious particles and for the feedback process by which more disease transmission in a building leads to more sick occupants who are sources of infectious particles. The theoretical model is calibrated, i.e., fit to several sets of empirical data, resulting in different curves relating ventilation rates with illness prevalence.

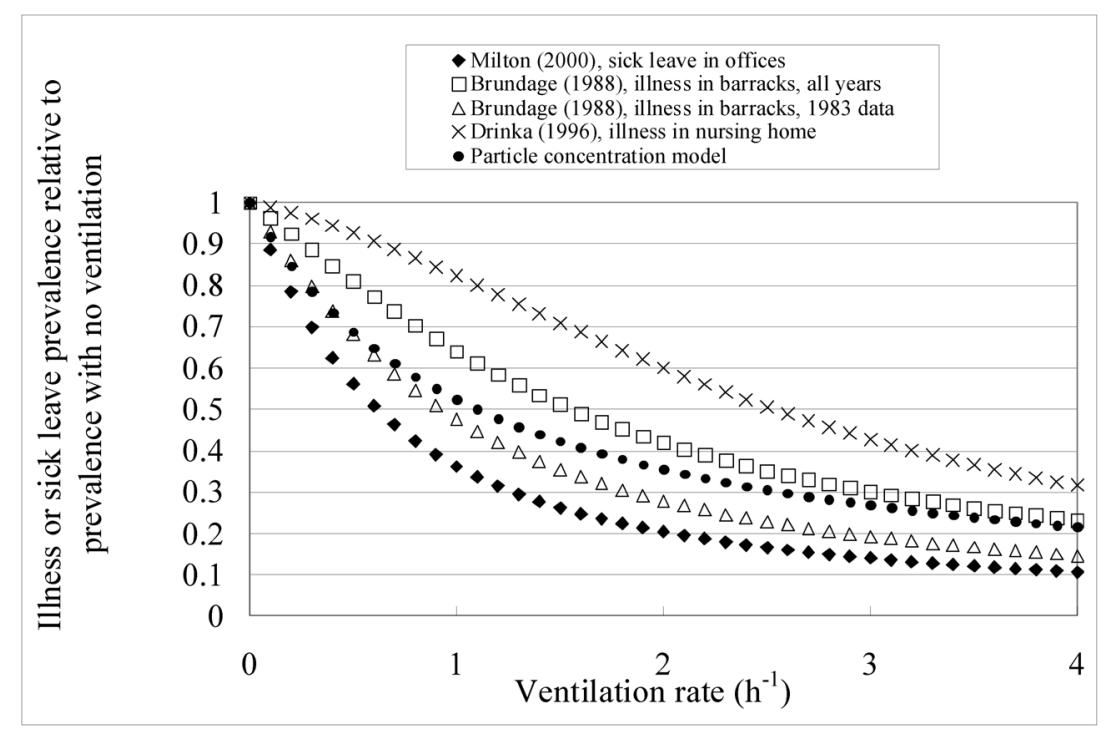

Figure 1. Predicted trends in illness of sick leave versus ventilation rate (from Fisk et al. 2003) 
The relationships of sick leave or absence with air change rate that are depicted in Figure 1 are only applicable for the levels of occupant density encountered in the studies. To illustrate how the illness or absence rate is predicted to vary with ventilation rate per person in an office building, Figure 2 provides a re-plot of two of the curves in Figure 1, assuming an occupant density of $2900 \mathrm{ft}^{3}\left(83 \mathrm{~m}^{3}\right)$ per person, which was derived using data from a survey of 100 U.S. office buildings (Burton et al. 2000).

From the data of Milton et al. (2000), one can derive a baseline short-term sick leave rate of $2 \%$ for an office building with a ventilation rate of $12 \mathrm{~L} \mathrm{~s}^{-1}$ per person, enabling a calculation of the annual average sick leave rate, for higher or lower ventilation rates. Applying the curve in Figure 2 based on the particle concentration model, which corresponds to a mid-range among the results depicted in Figure 1, , one can estimate that doubling the average ventilation rate to $24 \mathrm{~L} \mathrm{~s}^{-1}$ per person, would decrease the sick leave prevalence in an office from $2 \%$ ( 5 days per year) to $1.5 \%$ (3.8 days per year).

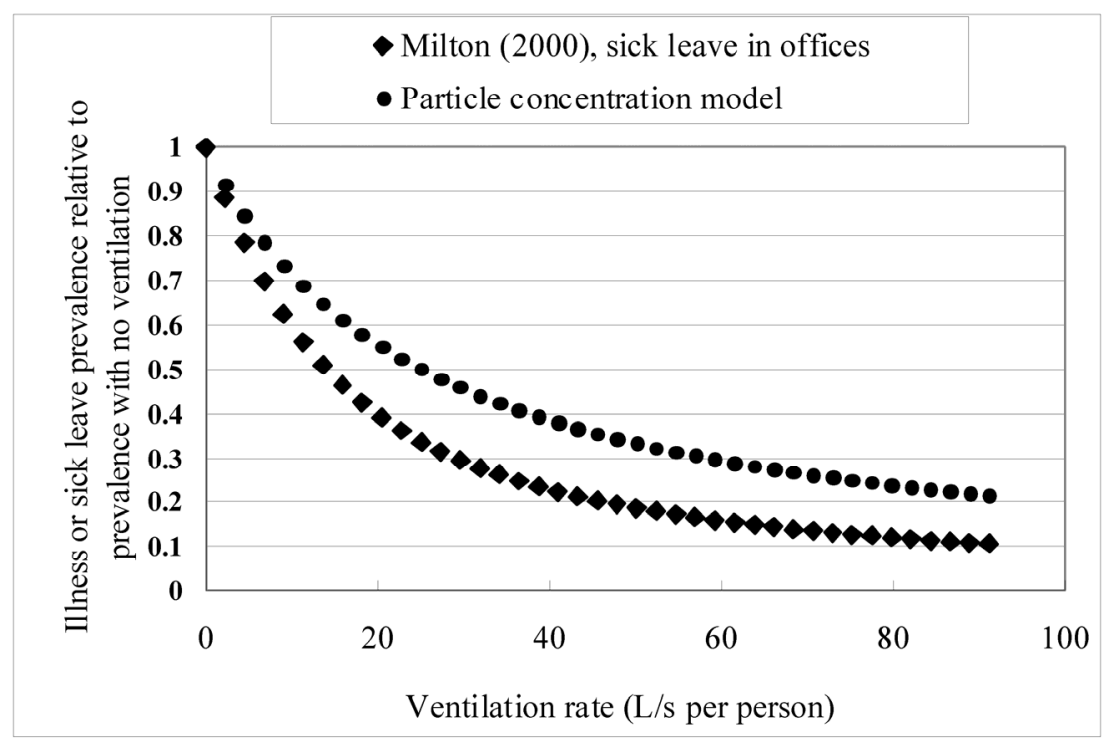

Figure 2. Predicted trends in illness or sick leave versus ventilation rate per person.

There are many sources of uncertainty in the model used to relate ventilation rates to sick leave. Most important is the limited empirical data available to calibrate and evaluate the model. In addition, there are uncertainties in the size, filtration rate, and deposition rate of infectious particles in typical buildings. Also, the natural loss of viability of airborne infectious particles has not been accounted for in the model due to a lack of information on the survival times of the airborne virus and bacteria that cause respiratory diseases. If suitable information were available, viability loss could be incorporated in the model as filtration and depositional losses were incorporated. The rate at which an infector disseminates infectious particles will likely vary among illnesses. The susceptibility to infection will vary with the age, health status, and immunizations of the occupants of the building. It is likely that these and other factors, including different amounts of time spent in different types of buildings, partially explain the different curves shown in Figure 1. Despite these large sources of uncertainty, a rough accounting of the influence of ventilation rates on sick leave may lead to better decisions about building design and operation than totally neglecting this issue. 


\section{VENTILATION RATES AND PERFORMANCE}

Ventilation affects productivity indirectly through its impact on short-term sick leave due to infectious diseases, but also directly. To establish the relation between ventilation rate and performance we identified five relevant workplace studies (Heschong group 2003, Federspiel et al. 2004, Tham 2004, Tham and Willem 2004, Wargocki et al. 2004), and two studies with data collected in controlled laboratory environment (Bako-Biro 2004, Wargocki et al. 2000a). All workplace studies were performed in call centres where the time required to talk with customers and the processing time between calls with customers, and other relevant information was automatically recorded in computer files. In these studies, the speed of work, i.e., time per call, was used as a measure of work performance. Laboratory studies assessed work performance by having subjects perform one or more computer-administered tasks that simulate aspects of actual work and by subsequent evaluation of the speed and/or accuracy of task performance. We also included a study made in schools using Swedish performance evaluation system with reaction times (Myhrvold and Olesen 1997). We used adjusted results when possible and unadjusted results when the authors made no adjustments. Some of the studies have compared only two ventilation rates some provide the data comparing several ventilation rates. We included in the summary all reported data points regardless of the level of the statistical significance, which actually was not reported in all studies

We normalised the data from the studies by calculating the change in performance per increase of $10 \mathrm{~L} / \mathrm{s}$-person in ventilation rate. Thus, the relative performance increase was calculated by subtracting the performance with the lower ventilation rate from the performance with the higher ventilation rate and dividing the difference, by performance by lower ventilation rate. This relative change in performance was further divided by the difference between the two ventilation rates in L/s-person, and multiplied by $10 \mathrm{~L} / \mathrm{s}$-person, and converted to percentages. The number represents thus the change in performance of a specific task per increase in ventilation rate of $10 \mathrm{~L} / \mathrm{s}$-person. The included studies also varied greatly in sample size and method. In the regression we weighted the studies by adjusted number of subjects. We also applied a weighting factor based on the authors' judgement of the relative relevance of the performance outcome to real work. We used the following relative weighting factors: overall work performance (1), single tasks (0.5) and reaction time (0.25). The sample size weight and outcome relevance weight were then combined to get a final set of weights (Seppänen et al. 2006). Normalized Adjusted Change in Productivity (\%) vs. ventilation rate, unweighted, weighted by sample size, and weighted by combined final weight are plotted in Figure 3. The very large (21.9\%) improvement in performance reported by Tham (2004) at a ventilation rate of $10 \mathrm{~L} / \mathrm{s}$-person compared to $5 \mathrm{~L} / \mathrm{s}$-person (when the temperature was $24.5^{\circ} \mathrm{C}$ ) was a clear outlier among the data and was excluded from the final analysis. Figure 3 shows also the $90 \%$ confidence limits for the model with composite weights. 


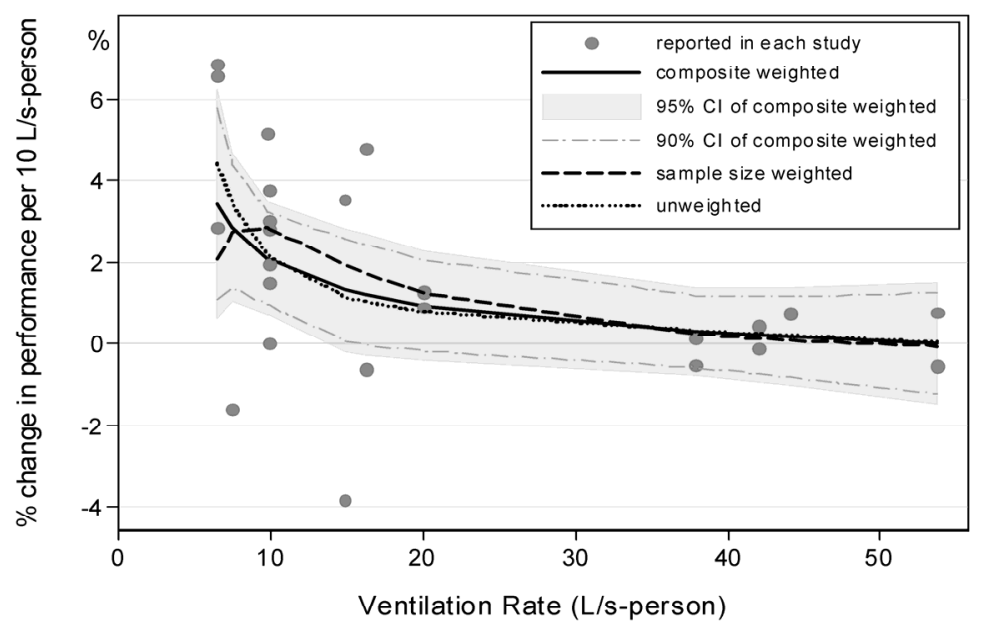

Figure 3. change in performance per $10 \mathrm{~L} / \mathrm{s}$-person increase in ventilation rate versus average ventilation rate in the experiment (data points), and regression models (curves). One outlier data point (43.8\% at $7.5 \mathrm{~L} / \mathrm{s}$-person) is excluded. Dashed line: no weighting factors; broken line: data points weighted by sample size as described in text; solid line: data points weighted by sample size and relevance of out come (composite weighted) as described in the text. The shaded area represents 95\% confidence interval and the dashed-dot line represents the $90 \%$ interval for the curve for with composite weights (solid line).

Figure 3 shows that the trend of increasing performance with increased ventilation rate is statistically significant ventilation rates up to approximately $16 \mathrm{~L} / \mathrm{s}$-person with $90 \% \mathrm{CI}$ and up to $14 \mathrm{~L} / \mathrm{s}$-person with $95 \% \mathrm{CI}$. In practise the equipment and energy cost also limit the ventilation rates. Based on the estimated polynomial models, the performance at all ventilation rates relative to the performance at a reference ventilation rates of $6.5 \mathrm{~L} / \mathrm{s}$-person and $10 \mathrm{~L} / \mathrm{s}-$ person were calculated and plotted in Figure 4. 

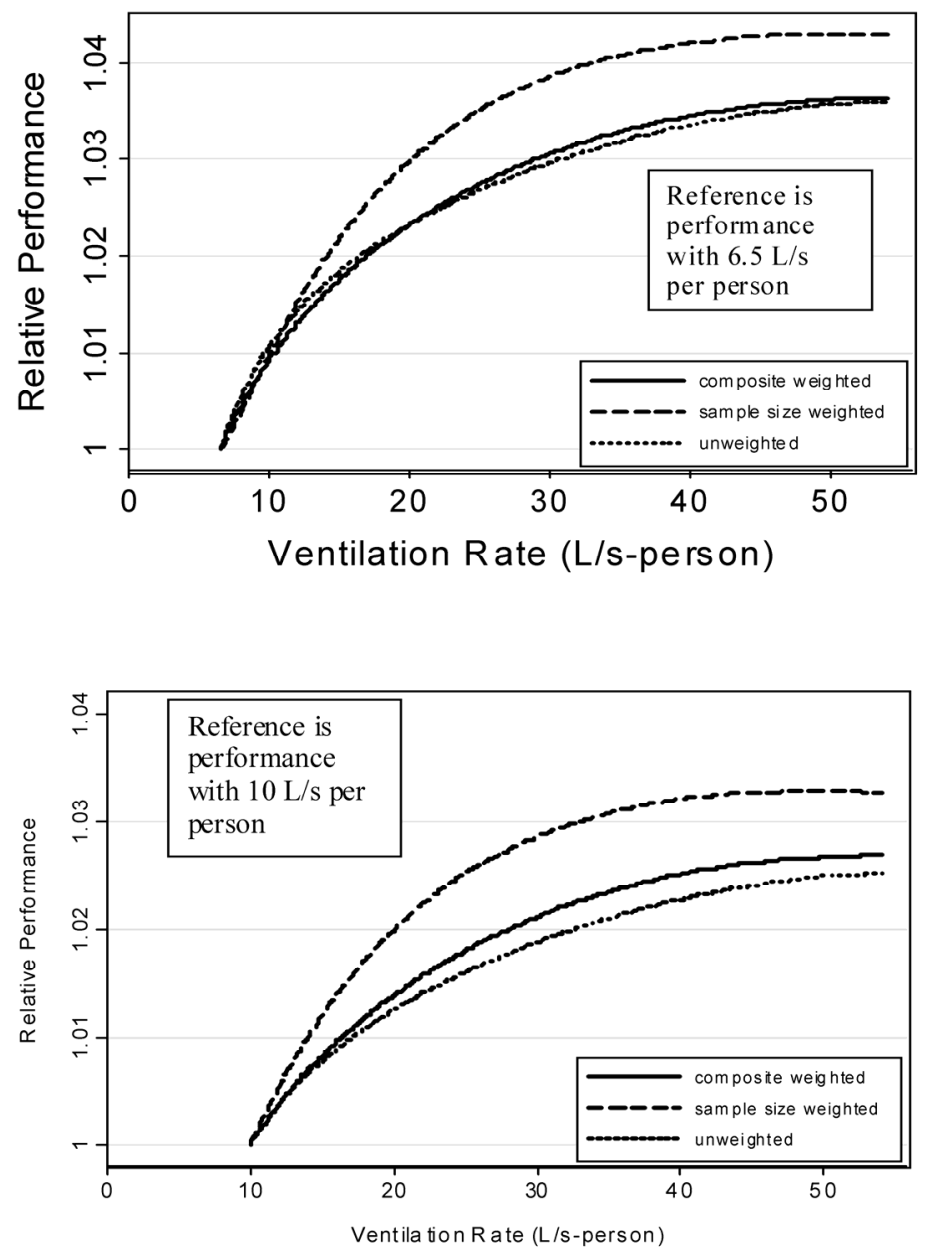

Figure 4. Relative performance in relation to the reference value at $6.5 \mathrm{~L} / \mathrm{s}$-person and 10 $L / s$-person versus average ventilation rate. Dashed line: no weighting factors; broken line: data points weighted by sample size as described in text; solid line: data points weighted by sample size and relevance of out come (composite weighted) as described in the text.

\section{PERCEIVED AIR QUALITY AND PERFORMANCE}

Sensory evaluations of air quality with the olf-decipol concept has been used as indicators of air quality since 1988 when they was first introduced (Fanger 1988). Sensory evaluation is an integrated measure of air quality as sensed by human senses (olfactory and facial nerves). Perceived air quality can be evaluated with trained or untrained olfactory panels. The trend during last years has been towards untrained panel whose members evaluate the air quality either acceptable or not acceptable for an eight hour occupancy. The percentage of panel members finding the air quality unacceptable (dissatisfied with air quality) is used as an indicator of air quality. This metrics seem to be more sensitive than evaluation of air quality with reference scales.

It is not clear that perceived air quality (PAQ) can directly affect work performance. However, if there is a consistent relationship between changes in PAQ and changes in work performance, we should be able to use that relationship to estimate how work performance is influenced by a variety of IEQ conditions that have previously been linked to PAQ. 
The studies reporting PAQ and performance have been performed mainly in Denmark. The first study (Wargocki et al. 1999) reported significantly $(\mathrm{P}<0.05)$ worse performance with text typing and addition tasks when the pollution source was present, and almost significantly $(\mathrm{P}<0.1)$ worse performance with errors in text typing, logical reasoning and serial addition and stroop tasks when the pollution source was present. Wargocki et al. (2000b) developed a model based on these results. The model shows $1.1 \%$ increase in performance of office work (text typing, addition and proof reading) for each 10\% decease in percentage dissatisfied with the air quality upon entering the space (first response and as a visitor to the space) (Figure 5). (The data apply for the air quality level causing dissatisfied from $25 \%$ to $70 \%$ ).

Wargocki et al. (1999) performed the experiment using a carpet removed from a sick building as a pollution source. The experiments were repeated later in Sweden (Lagencranz et al. 2000), with similar conditions. The results showed similar trend but not as strong as in the earlier experiments performed in Denmark. Bako-Biro 2004 continued the experiments exposing subjects in laboratory with pollutants from computer display terminals and from building materials. He reports similar effect as Wargocki (1999 and 2000a) but not so strong. He also combines the data from his own experiments and from previous experiments and presents a model for performance of text typing (combined speed and errors). His results imply that every $10 \%$ decrease in the percentage dissatisfied with the PAQ the performance of text typing can be improved by $0.8 \%$ (Figure 6) (The data apply for the air quality level causing $15 \%$ to $65 \%$ dissatisfied.

Based on the reviewed studies we do not, however, know whether lower perceived air quality is causally related to performance or only an indicator of some other factors in the building which have a causal relation to performance. The PAQ is affected by several factors. It depends mainly on pollutant sources and ventilation rate, but also on temperature and humidity.

Based on the models by Wargocki et al. (2000b) and Bako-Biro (2004) changes in perceived air quality can be used to predict changes in performance. Data from European Audit project (Bluyssen at al. 1996) showed that PAQ varied in European buildings between

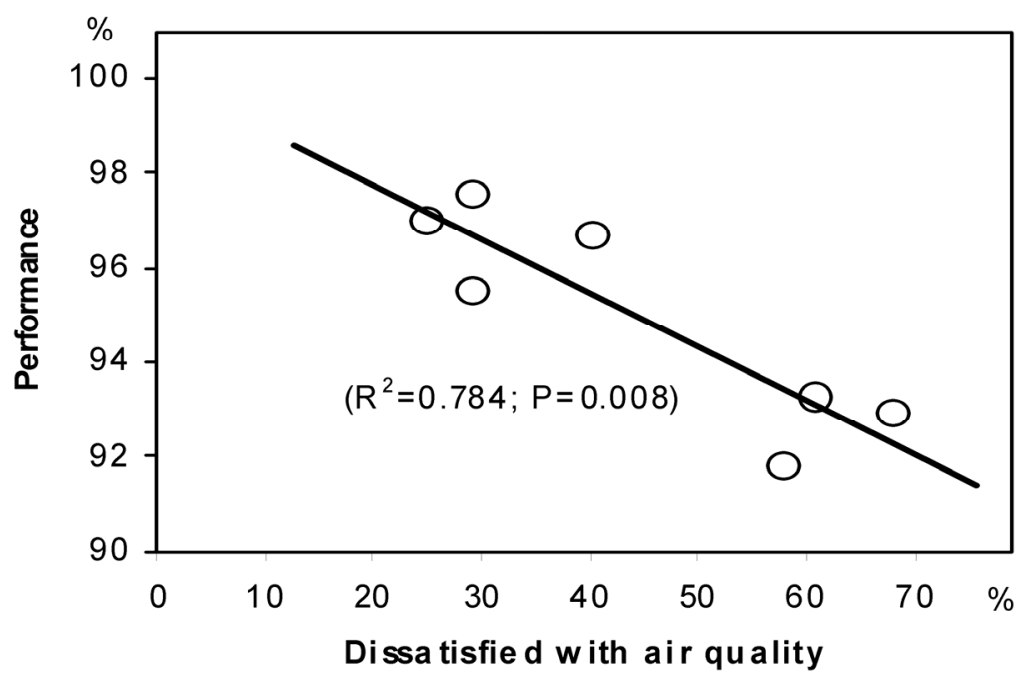

Figure 5. Relative performance in office work depending on the perceived air quality evaluated with untrained olfactory panel and expressed as percentage of dissatisfied with air quality (with permission from Wargocki et al. 2000b) 
2 and 9 decipols which corresponds $25-60 \%$ of dissatisfied. Using the model by Wargocki (2000b) this corresponds a potential improvement of $3.8 \%$ of performance in office tasks and by Bako-Biro (2004) potential improvement of $2.8 \%$ of performance range in text-typing.

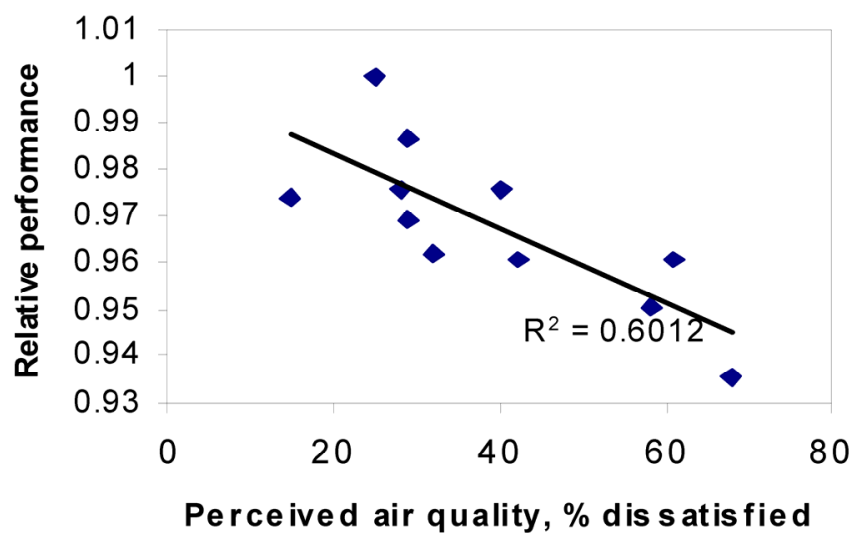

Figure 6. Relative performance in text-typing depending on perceived air quality expressed as percentage of dissatisfied with air quality (with permission from Bako-Biro 2004).

\section{TEMPERATURE AND PERFORMANCE}

In many commercial buildings, thermal conditions are not well-controlled due to insufficient cooling or heating capacity, high internal or external loads, large thermal zones, improper control system design or operation, and other factors. Thermal conditions inside buildings vary considerably with time, e.g., as outdoor conditions change, and spatially within buildings. While the effects of temperature on comfort are broadly recognized, the effects on worker productivity have received much less attention. For this linkage, we assembled existing information on how temperature affects performance so that these effects could be incorporated in cost benefit calculations related to building design and operation. Air temperature could influence productivity indirectly through its impact on SBS symptoms or satisfaction with air quality; however, for cost-benefit calculations it is most feasible to use the available data directly linking temperature, or thermal state, to performance.

We have earlier developed (Seppänen et al. 2003) a relation between performance and temperature It showed a decrease in performance by $2 \%$ per ${ }^{\circ} \mathrm{C}$ increase of the temperature in the range of $25-32{ }^{\circ} \mathrm{C}$, and no effect on performance in temperature range of $21-25^{\circ} \mathrm{C}$.

Several new studies have reported performance and temperature since the previous review. We have also been able to identify some old studies on performance related to office work which were not included in our earlier review. Various metrics of performance were used in these studies. Field studies used a work task as metrics of performance. In call centres the talk time or the total talk plus subsequent computer processing time have been used to indicate the level of performance. Laboratory studies typically measured performance in a single or combined task. Two studies measured a single task in the field conditions. Some studies reported objectively and subjectively measured performance data.

We reanalyzed the old and new studies (totally 150 assessments of performance from 26 studies). We calculated from all studies the percentage performance change with an increase 
in temperature of each assessment and divided that by temperature range of the assessment, yielding a slope in the performance-temperature relationship. The number derived by this way indicates percentage change in performance per degree increase in temperature, positive value indicating increase in performance with increasing temperature, and negative value indicating decrease in performance with increasing temperature.

The studies varied greatly in sample size and outcome. In the meta-analysis we weighted the data points in each study using the same principles as described in the previous section on "Performance and ventilation rate", by sample size and the relevance of the outcome. The weighting factor for the outcome type ranges from 0.15 to 1.0 depending on the relevance to the office work (details of weighting described by Seppänen et al. (2005b).

All data points derived by this way are presented in the Figure 5 with slope (i.e., percentage change in performance per ${ }^{\circ} \mathrm{C}$ increase in temperature) on the vertical axis and the average temperature of assessment on the horizontal axis. Positive values indicate improved performance and negative values poor performance with increasing temperature. The graph shows that performance increases with temperature up to $20-23{ }^{\circ} \mathrm{C}$, and that performance decreases with temperature above $23-24{ }^{\circ} \mathrm{C}$. The slope equals zero at a temperature of 21.6 ${ }^{\circ} \mathrm{C}$. The shaded area in the figure represents $90 \%$ confidence interval of the curve with composite weights. As can be seen, the $90 \%$ CI (shaded area) is positive up to temperature 20 ${ }^{\circ} \mathrm{C}$ and negative above $23{ }^{\circ} \mathrm{C}$, indicating that an increase of temperature up to $20{ }^{\circ} \mathrm{C}$ improves performance and increase of temperature above $23{ }^{\circ} \mathrm{C}$ decreases performance.

From "slope of the curve" in Figure 7, via an integration using the same basic method described in Seppanen et al (2006), we further developed a curve of performance in relation to maximum performance (Figure 8). For example, at the temperature of $30{ }^{\circ} \mathrm{C}$ the performance is $90 \%$ of the maximum performance at $21.6^{\circ} \mathrm{C}$, i.e. the reduction in performance is $10 \%$.

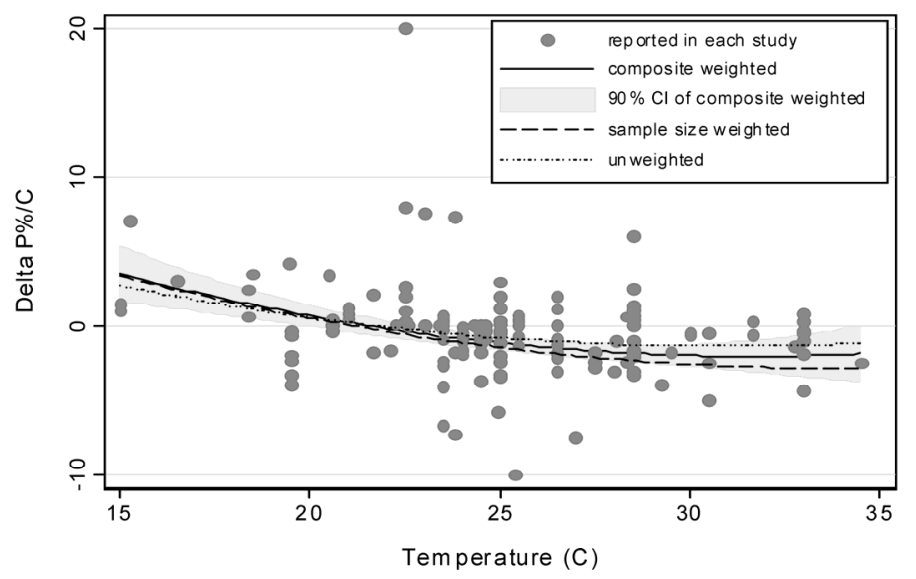

Figure 7. Change in performance per one degree C increase in temperature (Delta P\% per

${ }^{\circ} \mathrm{C}$ ) vs. temperature. Positive values indicate improved performance and negative values deteriorated performance with increased temperature. The chart has 148 data points from 26 studies. 


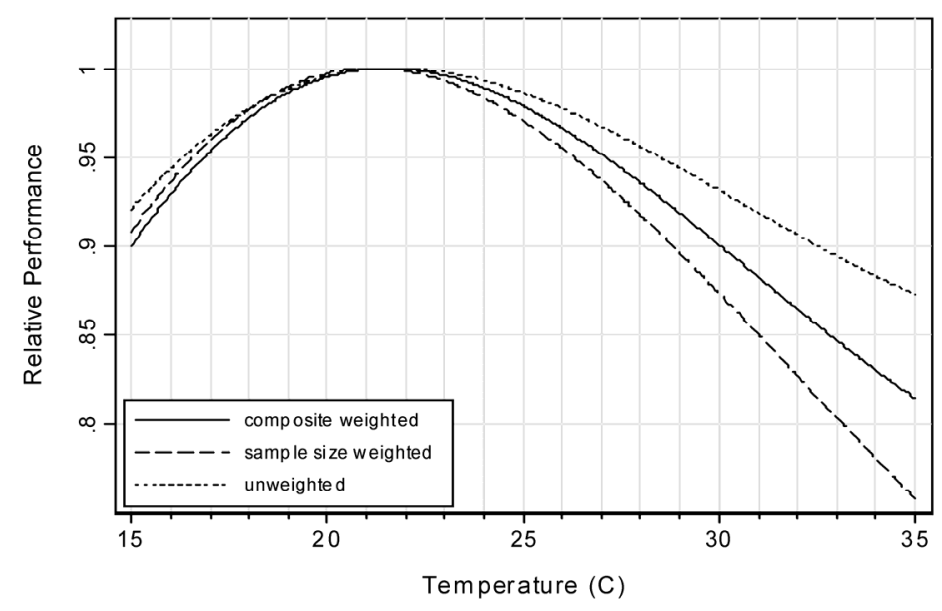

Figure 8. Relative performance vs. temperature derived from the curves in Figure 7. Maximum performance is set equal to 1 at the temperatures where the corresponding curves in the Figure 7 cross the horizontal axis.

\section{SBS-SYMPTOMS AND PERFORMANCE}

In many prior studies, characteristics of buildings and indoor environments have been linked to the prevalence of building-related SBS-symptoms experienced by the occupants of the building. For example, identified risk factors for SBS symptoms have included air conditioning (Seppänen and Fisk 2002), lower ventilation rate and higher carbon dioxide concentrations (Seppänen et al. 1999, Wargocki et al. 2002a), higher air temperature (Mendell 1993, Mendell et al. 2002), higher concentrations of some types of volatile organic compounds (Ten Brinke et al. 1998, Apte and Daisey 1999, Apte and Erdman 2002, excess dirt and moisture in HVAC systems (Mendell et al. 2003), and moisture problems in buildings (Park et al 2005). Because we already have considerable data relating building factors with SBS symptoms, it would be very useful if we could quantitatively relate the prevalence or intensity of SBS-symptoms to productivity and to rates of sick leave which are outcomes that can be quantified in economic terms.

We identified 24 studies (Table 2) which simultaneously reported the prevalence or intensity of SBS symptoms and a measure of work performance. From those, eight were field experiments and nine cross sectional field studies.

Fifteen field studies (either cross sectional or experimental) reported association between SBS-symptoms and self-assessed productivity in office environment. Four studies Niemelä et al. 2002,

Niemela et al. 2004, Tham 2004, Tham and Willem 2004) reported how objectively measured productivity was associated with SBS-symptoms in office environments. In addition two studies reported an association between SBS-symptoms and objectively measured performance in school environments (Myhrvold et al. 1996, Myhrvold and Olesen 1997).

In addition to field studies, five laboratory studies (Bako-Biro 2004, Lagercrantz et al. 2000, Nunes et al. 1993, Wargocki et al. 1999, Wargocki et al. 2000a) reported SBSsymptoms and objectively measured performance in tasks related to productivity in office work. Two laboratory studies used only self-reported performance (Fang et al. 2002 and Kaczmarczyk et al. 2002). These studies also report an association, but do not indicate a causal relationship, between increased SBS-symptoms and diminished objectively measured performance in tests that have tasks emulating real work. 
A formal meta-analysis of these data is problematic because the symptom data are collected with different questionnaires which may have used different symptoms and different recall periods. Some studies used symptom prevalence as an outcome, while other studies used symptom intensity. The criteria used to indicate that a person experiences a symptom has also varied among studies. For example, a criterion in one study might be that the subject experienced the symptom at least weekly, while another study might require that the subject experienced the symptom most days last week. In addition, some but not all studies considered only symptoms that improved when the subject was away from the building.

However, two recent studies with objective performance data suggest a relationship of SBS symptoms and performance. Niemela et al. (2004) suggest, based on data form a call center, that an average reduction of $7.4 \%$-points in the prevalence of weekly central nervous symptoms correspond with a $1.1 \%$ increase in productivity. Tham and Willem (2004) report a linear relationship between intensity of mean score of neurobehavioral symptoms and average talk time in a call center. The talk time improved (shortened) $5 \%$ per 10 points change in intensity of symptoms. The intensity of symptoms was measured with an analog-visual scale from 0 to 100 .

These observations support the hypothesis that a relationship exists, however, due the diversity of reported symptoms, and relative limited number of studies reporting the objectively measured symptoms we feel that we cannot yet develop a reliable relation between the symptoms and performance.

Table 2. Studies assessing simultaneously the prevalence or intensity of SBS symptoms and subjectively-reported or objectively-measured productivity outcomes by study type. There are a total of 24 studies.

\begin{tabular}{|l|l|l|l|}
\hline Study type & $\begin{array}{l}\text { Self-reported } \\
\text { and objectively } \\
\text { measured (2) }\end{array}$ & Self-reported (13) & Objectively measured (9) \\
\hline $\begin{array}{l}\text { Cross } \\
\text { sectional } \\
\text { field study } \\
(9)\end{array}$ & & $\begin{array}{l}\text { Chao et al. 2003, Hall et al. 1991, } \\
\text { Heslop, 2002, Heslop 2003 } \\
\text { Raw et al. 1990, Rohr and } \\
\text { Brightman 2003, Whitley et al. } \\
\text { 1995, Woods and Morey 1987 }\end{array}$ & Myhrvold et al.1996 \\
\hline $\begin{array}{l}\text { Experimental } \\
\text { field study } \\
(8)\end{array}$ & $\begin{array}{l}\text { Tham and } \\
\text { Willem 2004 }\end{array}$ & $\begin{array}{l}\text { Hedge et al. 1993, Menzies et } \\
\text { al.1997, Wyon et al. 2000, }\end{array}$ & $\begin{array}{l}\text { Myhrvold and Olesen } \\
\text { 1997, Niemelä et al. } \\
\text { 2002, Niemela et al. } \\
\text { 2004, Tham 2004 }\end{array}$ \\
\hline $\begin{array}{l}\text { Laboratory } \\
\text { experiment } \\
\text { (7) }\end{array}$ & $\begin{array}{l}\text { Bako-Biro } \\
2004\end{array}$ & $\begin{array}{l}\text { Fang et al. 2004, Kaczmarczyk et } \\
\text { al. 2002 }\end{array}$ & $\begin{array}{l}\text { Nunes et al. 1993, } \\
\text { Lagencrantz et al. 2000 } \\
\text { Wargocki et al.1999, } \\
\text { Wargocki et al. 2000 }\end{array}$ \\
\hline
\end{tabular}

\section{TEMPERATURE AND SBS-SYMPTOMS}

Many studies have also reported a linkage between high temperatures and higher prevalence or higher intensity of SBS symptoms, with a particularly strong link identified by Mendell et al. (2002). Studies may report only a few of recorded symptoms, some report all, and some use an index or score which combines multiple symptoms into a symptom group.

We made distinction between studies reporting intensity and prevalence. Jaakkola et al. (1989), Jaakkola et al. (1991) and Reinikainen et al. (2001) used a SBS-score which included all symptoms, Menzies et al. (1993 and 2003) reported prevalence of any symptoms, and Skov (1990) general symptoms from logistic regression model. We calculated from the given data the relative risk of SBS-symptoms in a given temperature range per ${ }^{\circ} \mathrm{C}$ using the 
exponential relation of prevalence per degree. If the relative risk was reported for a wider temperature range than one degree, we calculated relative risk for one degree from equation (1). When outcome prevalence is low the relative risk is approximately equal to the odds ratios (up to prevalence of $20 \%$ the RR (relative risk) is less than 10\% smaller than OR (odds ratio)). Thus, in our use of equation (1), we have used a reported OR or RR calculated from the given data.

$$
R R_{1^{\circ} \mathrm{C}}=R R_{\Delta T}^{1 / \Delta T}
$$

where

$R R_{1}{ }^{\circ} C=$ relative risk for increase in temperature of $1{ }^{\circ} \mathrm{C}$

$R R_{\Delta T}=$ relative risk for increase in temperature of $\Delta T$

$\Delta T=$ reported temperature range in the assessment or unit of temperature change used in models in the study, ${ }^{\circ} \mathrm{C}$

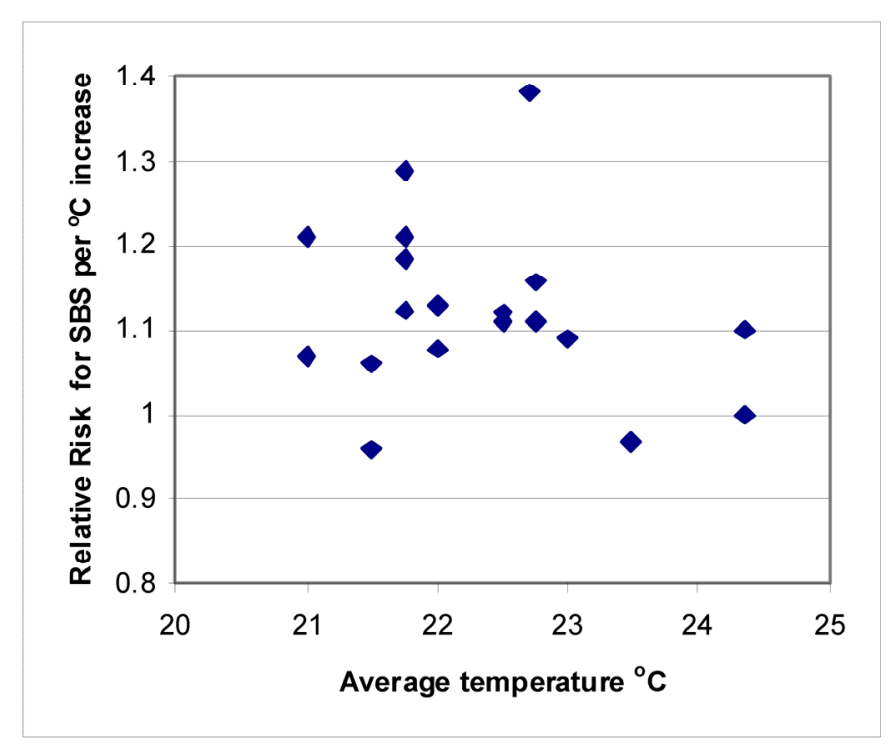

Figure 9. Relative risk of SBS symptoms per $1{ }^{\circ} \mathrm{C}$ increase in temperature versus average temperature of the assessment. There were 20 assessments from six studies.

In Figure 9, we plotted these data points with the average temperature of the reported temperature range as the horizontal axis. With two exceptions the relative risk per $1{ }^{\circ} \mathrm{C}$ increase in temperature is greater than one. The average relative risk $\left(R R_{a v}\right)$ equals 1.123 per 1 ${ }^{\circ} \mathrm{C}$ increase in temperature in the temperature range of $20-25{ }^{\circ} \mathrm{C}$. All studies reporting the prevalence of symptoms were performed in non-problem buildings in cold or moderate climate in the winter when the relative humidity was below $30 \%$ with one exception of $40 \%$.

Three of the studies reporting the intensity of symptoms were made in the field in non problem buildings (Mendell et al. 2002, Tham 2004, Tham et al. 2003) and two were performed in the laboratory (Fang et al. 2004, Kaczmarczyk et al. 2002). The summary of these studies indicated a $12 \%$ increase in the intensity of SBS-symptoms per $1{ }^{\circ} \mathrm{C}$ increase temperature above $22.5^{\circ} \mathrm{C}$.

The summaries suggest that increased temperatures increase also the prevalence and intensity of SBS symptoms which may further affect absence from work and performance. 


\section{DISCUSSION}

This paper demonstrates that we now have enough data to begin to account quantitatively for the influence of IEQ and related building conditions on worker health and productivity. Based on the reviewed literature, we were able to estimate quantitatively how ventilation rates, temperatures, and perceived air quality are related with health and work performance outcomes. We also show that a relation between SBS symptoms and decreased productivity is strongly suggested by the available data and note that reliable functions relating SBS symptoms to productivity or absence would be very valuable because there are many existing data relating building design and operation to SBS symptom prevalences.

There are many limitations that apply to the quantitative relationships that we have derived. The most important limitation is that the current estimated relationships have been derived, in most cases, based on data from a rather modest number of studies. Consequently, all of these estimates have a high level of uncertainty. In derivation of quantitative relationships, we have also assumed that the observed associations indicate a causal relationship, or that the association is robust enough that one can use it to predict changes in health and performance. For example, it is rather certain that high air temperature can actually degrade work performance, because the effects have been demonstrated in intervention studies with other factors held constant. However, we know that ventilation rate does not directly influence performance - it can only influence some other factor(s) such as air pollutant concentrations that in-turn affect work performance. The reliance on the relationship of perceived air quality with performance is most uncertain. Perceived air quality could be a surrogate for a host of other factors that may affect performance; however, it is not certain that each factor that influences perceived air quality also affects work performance.

There are several other important limitations or important cautions about use of the quantitative estimates provided in this paper, including the following:

- Currently we have estimates about the population-average effects of IEQ and related building factors on health and performance. We recognise that responses to IEQ will vary among individuals and with the type of work being performed. Perhaps, only the more susceptible portion of the population may by adversely affected by poor IEQ. Theoretically, it would be more cost effective to target the remedial actions on those who suffer most from indoor environmental conditions; however, such a targeted response will often be impractical.

- The quantitative relationship between a building feature or IEQ condition and health and productivity will also vary among buildings. For example, increased ventilation rates may be highly beneficial in a building with strong indoor pollutant sources and only marginally beneficial in buildings with below-average pollutant sources. Our estimates of quantitative relationships between IEQ and health and productivity are best estimates for the average building. Hence, uncertainty about the magnitude of benefits in a specific building may remain as an obstacle to IEQ improvements, even when average benefits can be estimated. To the degree possible, the application of the cost-benefit calculations to evaluate design options or operational procedures in specific buildings should be performed using building specific data. In general, remedial measures would be expected to be more cost effective in buildings that have poorer initial IEQ or more existing adverse health or comfort complaints.

- It is also important to note that when the benefits from the indoor environmental improvements are estimated, one cannot always simply add the benefits of each separate indoor environmental improvement measure, as their effects may overlap. Also, special care is needed when combining estimates of the benefits of improved perceived air quality with estimates of the benefits of other factors, as perceived air quality is only a surrogate for other factors that may affect work performance. 
- The extent to which an employer can capitalize on productivity gains from better IEQ may also depend on the type and size of the employer. An increase of performance will be more important when the work is labour intensive, and may be more practical for large companies. For example a ten-person company would not be able to decrease its staff after an IEQ improvement that increased productivity by a few percent, while a company with hundreds or thousand of workers could adjust their workforce. But even in a small company the productivity increase may lead to higher profits.

- The market situation may also affect the degree to which potential benefits motivate efforts to improve IEQ. A speculative builder may be interested only in the short-term return of the investment. A lesser may let the indoor environmental quality of the building deteriorate by saving money on maintenance and accept (or be unaware of) the decrease in rental income and value of the property.

We acknowledge the high level of uncertainty associated with the incorporation of productivity in cost-benefit calculations related to building design and operation. However, we believe that estimating productivity benefits using the best available information will generally lead to better decisions about building design and operation than the current practice of ignoring the potential benefits.

\section{CONCLUSIONS}

For cost-benefit analyses leading to improved IEQ, health and productivity, it is not sufficient to have information demonstrating a statistically-significant association between an IEQ condition and health or performance, the size of that effect must be estimated quantitatively. In this paper we have shown that it is possible, with existing data, to estimate quantitative relationships between ventilation rate and illness-caused absence, and to estimate quantitatively how work performance relates with ventilation rate, air temperature, and perceived air quality.

These resulting quantitative relationships have a high level of uncertainty; however, use of these relationships may be preferable to the current practice which ignores health and performance related productivity in decisions about building design or operation.

\section{ACKNOWLEDGEMENTS}

This work was supported by the Academy of Finland. This work was also supported by the Indoor Environments Division, Office of Radiation and Indoor Air, Office of Air and Radiation of the U.S. Environmental Protection Agency through interagency agreement DW89-92175001-0 with the U.S. Department of Energy. This work was also supported by the Assistant Secretary for Energy Efficiency and Renewable Energy, Office of Building Technology of the U.S. Department of Energy under contract DE-AC03-76SF00098. The authors would also like to thank QH Lei for help with statistical analyses, and Mark Mendell and Mike Apte for their valuable comments on the paper.

\section{REFERENCES}

Apte MG and Daisey JM. 1999. VOCs and "Sick Building Syndrome": Application of a New Statistical Approach for SBS Research to U.S. EPA BASE Study Data, in Proceedings of the 8th International Conference on Indoor Air Quality and Climate, August 8-13, 1999, Edinburgh, Scotland

Apte MG and Erdmann CA. 2002. Association of indoor carbon dioxide concnetrations, VOCs and environmental susceptibilies with mucous mebrane and lower resipratory sick builidng syndromesymptoms in the BASE study: Analyses of the 100 building data set, Lawrence Berkeley National Laboratory, Report LBNL-51570. 
VOCs and "Sick Building Syndrome": Application of a New Statistical Approach for SBS Research to U.S. EPA BASE Study Data, in Proceedings of the 8th International Conference on Indoor Air Quality and Climate, August 8-13, 1999, Edinburgh, Scotland

Bako-Biro Z. 2004. Human perception, SBS symptoms and performance of office work during exposure to air polluted by building materials and personal computers. Ph.D. Thesis. International Centre for Indoor Environment and Energy. Technical university of Denmark.

Bluyssen P, de Oliviera Fernandes E, Groes L, Clausen G, Fanger PO, Valbjørn O, Bernhard C, Roulet C. 1996. European indoor air quality audit project in 56 office buildings. International Journal of Indoor Air Quality and Climate. Vol 6, No. 4.

Brundage J, Scott R, Wayne M. et al. (1988) Building -Associated Risk of Febrile Acute Respiratory Diseases in Army Trainees. JAMA. Vol. 259 (14), pp 2108- 2112.

Burton LE, Baker B, Hanson D, Girman JG, Womble SE, McCarthy JF. 2000. Baseline information on 100 randomly selected office buildings in the United States (BASE): gross building characteristics. Proceedings of Healthy Buildings 2000, Vol. 1 151-155. www.isiaq.org

Chao HJ, Schwartz J, Milton DK, Muilenberg ML, Burge HA. Effects of indoor air quality on office workers performance - a preliminary analysis. In: Proceedings of 7 th International Conference of Healthy Buildings 2003, Singapore. 3: 237-243.

Djukanovic R, Wargaock, R, Fanger P. 2002. Cost-benefit analysis of improved air quality in an office building. Proceedings of Indoor Air 2002 pp. 808-813.

Drinka P, Krause P, Schilling M. 1996. Report of and outbreak: Nursing home architecture and influenza-A attack rates, $J$ Am Geriatric Society 44:910-913.

Fang L, Wyon DP, Clausen G, Fanger PO. 2004. Impact of indoor air temperature and humidity in an office on perceived air quality, SBS symptoms and performance. Indoor Air Journal 14 (Suppl 7) 74-81.

Fanger PO, 1988. Introduction of the olf and decipol units to quantify air pollution perceived by humans indoors an outdoors. Energy and buildings, 12:106.

Federspiel CC, Fisk WJ, Price PN, Liu G, Faulkner D, Dibartolemeo DL, Sullivan DP, Lahiff M. 2004. Worker performance and ventilation in a call center: analyses of work performance data for registered nurses. Indoor Air Journal vol 14. Supplement 8: 41-50.

Fisk WJ. 2001. Estimates of potential nationwide productivity and health benefits from better indoor environments: an update. In: Spengler, J. Sammet, J. and MacCarthy, J. eds. Indoor Air Quality Handbook, McGraw Hill

Fisk WJ. 2000. Health and productivity gains from better indoor environment and their relationship with building energy efficiency. Annual Review of the Energy and the Environment, vol 25. 2000. pp 537-566.

Fisk WJ, Seppänen O, Faulkner D, Huang J. 2003. Economizer system cost effectiveness: accounting for the influence of ventilation rate on sick leave. Proceedings of ISIAQ $7^{\text {th }}$ International Conference Healthy Buildings 2003, December 7 - 12, Singapore, vol 3, pp. 361-367.

Hall H, Leaderer B, Cain W, Fidler A.1991. Influence of building-related symptoms on selfreported productivity. Proceedings of Healthy Buildings/IAQ 91 conference pp 33-35

Hedge A, Mitchell G, McCarthy J, Ludwig J.1993. Effects of a furniture-integrated breathing zone filtration system on indoor air quality, sick building syndrome, productivity and absenteeism, Proceeding of Indoor Air 93 Vol 5 pp 383-388

Hansen, S.-O. 1997. Economical consequences of poor indoor air quality and its relation to the total building operation costs. EuroFM/IFMA Conference \& Exhibition, Torino, Italy June 1997 
Heschong Mahone Group. 2003. Windows and offices: A study of office workers performance and the indoor environment. Prepared for California energy commission. Fair Oaks, California.

Heslop K. 2002. Personal and environmental characteristics, occupational factors and psychososial correlates of sick building syndrome. Proceedings of Indoor Air 2002, pp $432-437$.

Heslop K. 2003. The influence of sick building syndrome on self-reported productivity and work disruption amongst office employees in two buildings in South Africa. In: Proceedings of 7th International Conference of Healthy Buildings 2003, Singapore. Vol 3 pp. 387-292.

Jaakkola JJK and Heinonen OP. 1989. Sick building syndrome, sensation of dryness and thermal comfort in relation to room temperature in an office building: need for individual control of temperature, Environment International, 15:163-168.

Jaakkola JK, Reinikainen LM, Heinonen OP, Majanen A Seppänen O. 1991. Indoor air quality requirements for health office buildings: recommendations based on an epidemiological study, Environment International, 17: 371-378.

Kaczmarczyk J, Zeng Q, Melikov A, Fanger PO. 2002. The effect of a personalized ventilation system on perceived air quality and SBS symptoms. In Indoor Air 2002: Proceedings of the $9^{\text {th }}$ International Conference on Indoor Air Quality and Climate, vol 4, Levin, H. ed., Indoor Air 2002, Santa Cruz, California, pp. 1042 - 47

Lagencranz L, Wistrand M, Willen U, Wargocki P, Witterseh T, Sundell J. 2000. Negative impact of air pollution on productivity: previous Danish findings repeated in new Swedish test. Proceedings of the Healthy Buildings 2000 Conference, vol 2:653-658.

Mendell MJ.1993. Non-specific symptoms in office workers: a review and summary of the epidemiologic literature. Indoor Air 1993;3:227-36.

Mendell MJ, Fisk WJ, Petersen MR, Hines CJ, Dong M, Faulkner D, Deddens JA, Ruder AM, Sullivan D and Boeniger MF. 2002. Indoor particles and symptoms among office workers: result from a double -blind cross-over study. Epidemiology, 13: 296-304.

Mendell MJ, Naco GN, Wilcox TG, Sieber WK. 2003. Environmental Risk Factors and Work-Related Lower Respiratory Symptoms in 80 Office Buildings: An Exploratory Analysis of NIOSH Data. Amer J Industrial Medicine 43:630-41.Menzies D, Pasztor J , Nunes F, Leduc J, Chan C (1997). The effect of a new ventilation system on health and well being of office workers. Arch. Environ. Health 52 (5): 360-67.

Menzies D, Popa J, Hanley JA, Rand T, Milton DK. 2003. Effect of ultraviolet germicidal lights installed in office ventilation systems on workers' heath and wellbeing: double blind multiple crossover trial. The Lancet. Vol 362. Pp 1785-1791.

Menzies R. Tamblyn R, Farant JP, Hanley J, Nunes F. 1993. The effect of varying levels of outdoor -air supply on the symptoms of sick building syndrome. N. Engl. J Med. 328:821827.

Milton, K., Glenross, P., Walters, M. 2000. Risk of Sick leave associated with outdoor air supply rate, humidification, and occupant complaint. International Journal of Indoor Air Quality and Climate, 10:211-221.

Myhrvold A, Olsen E, Lauridsen O.1996. Indoor environment in schools / pupils health and performance in regard to $\mathrm{CO}_{2}$ concentrations, Proceedings of the Indoor Air 1996 conference, Vol 4: 369 - 374

Myhrvold A, Olesen E.1997. Pupils health and performance due to renovation of schools. Proceeding s of Healthy Buildings/IAQ 1997. 1:81-86

Niemela R, Seppänen O, Reijula K. 2004. Prevalence of SBS-symptoms as indicator of health and productivity in office buildings. Submitted to American Journal of Industrial Medicine. 
Niemelä R, Hannula M, Rautio S, Reijula K and Railio J. 2002. The effect of air temperature on labour productivity in call centres - a case study. Energy and Buildings, Vol 34, 759764.

Nunes F, Menzies R, Tamblyn R, Boehm E, Letz R.1993. The effect of varying level of outdoor air supply on neurobehavioral performance function during a study of sick building syndrome (SBS). Proceedings of Indoor Air 93, vol 1:53-58

Park JH, Schleiff PL, Attfield MD, Cox-Ganser JM, Kreiss K. 2004. Building related respiratory symptoms can be predicted with semi-quantitative indices of exposure to dampness and mold. Indoor Air 14(6): 425 - 433.

Raw G, Roy M, Leaman A .1990. Further findings from the office environment survey. Proceedings of Indoor Air 90 conference, vol 1 pp 231-236

Reinikainen LM and Jaakkola JJK. 2001. Effect of temperature and humidification in the office environment. Arch. Environ. Health. Vol 56: 365-368.

Rohr AC, Brightman H. 2003. Effects of characteristics on self-reported productivity of office workers: the base study. In: Proceedings of 7th International Conference of Healthy Buildings 2003, Singapore. Vol 3 pp. 231-236.

Seppänen, O. 1999. Estimated cost of indoor climate in Finnish buildings. Proceedings of Indoor Air 1999, vol 3 pp. 13-18.

Seppänen O and Fisk W. 2002. Association of Ventilation Type with SBS symptoms in Office Workers. Indoor Air J. 12, 2:98-112.

Seppänen O, Fisk WJ. 2003. A conceptual model to estimate cost effectiveness of the indoor environment improvements. Proceedings of the International conference of Healthy Buildings. Singapore 2003.

Seppänen O, Fisk WJ and Faulkner D. 2003. Cost benefit analysis of the night-time ventilative cooling. In: Proceedings of the Healthy Buildings 2003 Conference. Singapore 2003, Vol 3:394-399

Seppänen O Fisk W, Mendell M. 1999. Association of Ventilation Rates and $\mathrm{CO}_{2}$ Concentrations with Health and other Responses in Commercial and Institutional Buildings. International Journal of Indoor Air Quality and Climate. 9:226-252.

Seppänen O. and Fisk WJ. 2002. Association of ventilation system type with SBS symptoms in office workers. Indoor Air 12(2): 98-112.

Seppänen O, Vuolle M. 2000. Cost effectiveness of some remedial measures to control summer time temperatures in an office building. Proceedings of Healthy Buildings 2000, vol 1, pp. 665-670.

Seppänen O, Fisk WJ, Lei QH. 2006. Ventilation and performance in office work. International Journal of Indoor Air Quality and Climate 16: 28-36.

Seppänen O, Fisk WJ, Lei QH 2005b. Effect of temperature on task performance in office environment. A manuscript under preparation..

Skov P, Valbjorn O, Pedersen BV, and Group T.D.I.C.S. 1990. Influence of indoor climate on the sick building syndrome in an office environment. Scandinavian Journal of Work, Environment and Health. 16: 363-371.

Ten Brinke J, Selvin S, Hodgson AT, Fisk WJ, Mendell MJ, Koshland CP and Daisey JM.1998. Development of new VOC exposure metrics and their relationship to sick building syndrome symptoms, Indoor Air 8(3): 140-152.

Tham KW. 2004. Effects of temperature and outdoor air supply rate on the performance of call center operators in the tropics. Indoor Air Journal 14 (Supp1 7):119-125.

Tham KW, Willem, HC. 2003. A principal component analysis of perception and SBS symptoms of office workers in the tropics at two temperatures and two ventilation rates. Proceeding of Healthy Buildings Conference 2003. Vol 3: 88-94. 
Tham KW, Willem HC. 2004. Effects of reported neurobehavioral symptoms on call center operator performance in the tropics. Proceedings (in CD) of RoomVent 2004 Conference. Coimbra. Portugal

Tuomainen M, Smolander J, Korhonen P, Eskola L, Seppänen O. 2003. Potential economic benefits of balancing air flows in an office building. Proceedings of Healthy Buildings 2003 Conference. Singapore. December 2003. Vol 2, 516-521.

Wargocki P. 2003. Estimate of economic benefits from investment in improved indoor air quality in office building. Proceedings of Healthy Buildings 2003 Conference. Singapore. December 2003. Vol 3, 383-387.

Wargocki W, Sundell J, Bischof W, Brundrett G, Fanger O, Gyntelberg F, Hanssen SO, Harrison P, Pickering A, Seppänen O, Wouters P (2002a) Ventilation and health in nonindustrial indoor environments. Report from a European Multidisciplinary Scientific Consensus Meeting. International Journal of Indoor Environment and Health.12:113-128.

Wargocki P, Wyon DP, Baik YK, Clausen G, Fanger PO. 1999. Perceived air quality, Sick Building Syndrome (SBS) symptoms and productivity in an office with two different pollution loads, Indoor Air J. vol 9: 165-179.

Wargocki P, Wyon DP and Fanger PO. 2000b. Pollution source control and ventilation improve health, comfort and productivity. In: Proceeding of Cold Climate HVAC '2000, Sapporo, pp. 445-450

Wargocki P, Wyon DP, Fanger PO. 2004. The performance and subjective responses of callcenter operators with new and used supply air filters at two supply air flow rates. Indoor Air J. vol 14. Indoor Air Journal vol 14. Supplement 8: 7-16

Wargocki P, Wyon D, Sundell J, Clausen G, Fanger PO. 2000a. The effects of outdoor air supply rate in an office on perceived air quality, sick building syndrome (SBS) symptoms and productivity, International Journal of Indoor Air Quality and Climate, vol 10:222-236.

Whitley T, Makin P, Dickson D.1995. The environment, comfort and productivity: the role of individual differences including locus of control. Proceedings of Healthy Buildings '95, vol 3: $1419-1424$.

Woods J, Morey G. 1987. Office workers perception of indoor air quality effects on discomfort and performance, Proceedings of Indoor Air 1987, 2:464-68

Wyon D, Tham K, Crocford A, Oreszczyn T. 2000. The effect on health and self-estimated productivity of two experimental interventions which reduced airborne dust levels in office premises. Proceedings of Healthy Buildings 2000 conference, vol 1, pp 641-646. 